\title{
PRODUÇÃO DE METABÓLITOS NO ARMAZENAMENTO DE UVAS 'ISABEL' (Vitís labrusca L.) E SUA RELAÇÃO COM TEMPERATURA E VÁCUO
}

\author{
METABOLITES PRODUCTION DURING THE STORAGE OF 'ISABELLA' GRAFES \\ (Vitis labrusca L.) AND ITS RELATIONSHIP TO THE \\ TEMPERATURE AND VACUUM
}

\author{
Gildo Almeida Da Silva ${ }^{1}$
}

RESUMO

Este trabalho teve por objetivo avaliar as transformações fisiológicas que ocorrem na uva 'Isabel' (Vitís labrusca $L$.), em diferentes condições de armazenamento. As uvas foram conservadas em temperatura ambiente $\left(25^{\circ} \mathrm{C}\right)$ e sob refrigeração $\left(4^{\circ} \mathrm{C}\right)$ e mantidas em dessecadores com aplicação de vácuo (-60kPa), no início do processo de armazenamento, e sem aplicação de vácuo. Os metabólitos produzidos foram analisados por cromatografia gás-líquida. Foi utilizado o delineamento experimental inteiramente casualidade, com duas repetições. A refrigeração reduziu a produção de etanol e de metanol. A formação de acetato de etila não foi afetada pelo vácuo ou pela temperatura isoladamente, mas depende da interação desses dois falares. A produção de etanol dependeu da interação temperatura-vácuo. A aplicação de vácuo aumentou a produção de etanol em temperatura ambiente. A refrigeração diminuiu a quantidade de bagas danificadas e a aplicação do vácuo teve um efeito oposto. Os resultados obtidos com a cultivar Isabel sugerem que o procedimento de aplicar vácuo $m$ início do processo de armazenamento de uva pode induzir dano físico às bagas até mesmo sob refrigeração e que, pela correlação observada, a deterioração da uva Isabel armazenada pode ser monitorada, analisando a concentração de etanol, metanol e eternal.

Palavras-chave: etanol, metanol, eternal, acetato de etila.

\section{SUMMARY}

In this research, the physiological transformations of 'Isabella' (Vitis labrusca L) grapes aí different storage conditions were examined. The grapes were stored at $25^{\circ} \mathrm{C}$ (nonchilled) and $4^{\circ} \mathrm{C}$ (chilled) crnd maintained $\mathrm{m}$ a desiccator with vacuum (-60kPa) appiication at lhe beginning of the storage process and without vacuum appiication. The metabolites produced were quantitativety determined by gas-liquid chromatography and statistically analysed using a completely randomized design with two repetitions. The chilling storage reduced the production of both ethanol and methanol. The ethyl acetato formation did not depena on the individual effects of vacuum and temperature but is affected by the interaction ofthese two factors. The ethanol production was increased by vacuum at room temperature and by the interaction temperature-vacuum. The chilling storage diminished the amount of damaged berries and the vacuum had an opposite effect. The results obtained with the cultivar Isabella suggest that the procedure of appiying vacuum at the beginning ofthe grape storage process may induce physical damage even ai chilling storage. The correlation studies show that the deterioration of stored Isabella table grapes can be readily monitored byfollowing the methanol, ethanol and ethanal production.

Key words: ethanol, methanol, ethanal, ethyl acetato.

\section{INTRODUÇÃO}

Alguns produtos agrícolas não permitem, para a conservação, o emprego de determinados tratamentos físicos, como baixas temperaturas (JACKMAN et al., 1992) e branqueamento (RICHARDSON \& HYSLOP, 1985). No caso de uvas de mesa, a vida de prateleira é um aspecto importante a considerar, pois está diretamente relacionada com as alterações que ocorrem nas bagas. Essas mudanças podem acontecer por mecanismos fisiológicos ou microbiológicos, ou ainda por combinação desses dois processos.

${ }^{1}$ Biomédico, PhD., Embrapa Uva e Vinho, CP 130, 995700-000, Bento Gonçalves - RS. E-mail: gildo@ cnpuv.embrapa.br. 
A pectina, encontrada na lamela média das plantas, pode ser atacada por enzimas pécticas. O teor de pectina da uva se situa entre 0,2 a $1,0 \%$ (FOGARTY \& WARD, 1972). Pectinametilesterase (EC 3.1.1.11) é amplamente distribuída em plantas (PRESSEY \& WOODS, 1992; RILLO et al., 1992) e suas propriedades e atividades têm sido bem estudadas (MANJÓN et al., 1992; LIU et al., 1992). Esta enzima cliva metil ésteres de pectina, produzindo metanol e ácido péctico. Este último é parcialmente degradado a ácido D-galacturônico, através de uma poligalacturonase (EC 3.2.1.15). Esta enzima é crucial para a textura de frutas e legumes (WHISTLER \& DANIEL, 1985) e, portanto, está envolvida diretamente no processo de amolecimento. Assim, a taxa de formação de metanol pode estar diretamente relacionada com a velocidade de deterioração do fruto.

Além da pectina, as hexoses, que estão abundantemente presentes nas bagas de uva maduras, podem ser igualmente atacadas por suas próprias enzimas, dando origem a quantidades significativas de produtos, entre os quais se destacam o etanol, etanal e acetato de etila. O metabolismo anaeróbico das uvas é complexo e envolve uma série de reações bioquímicas (RIBÉREAU-GAYON et al., 1976). A detecção de produtos finais ou intermediários formados pela ação das enzimas das próprias células vegetais é de interesse porque pode revelar sinais de deterioração.

Quando permitido, o armazenamento abaixas temperaturas é a prática mais comum para controlar amadurecimento, reduzir a deterioração e maximizar a vida de prateleira de frutas. Com a finalidade de minimizar o processo de deterioração, geralmente, empregam-se baixas temperaturas aliadas ao procedimento de atmosfera controlada (AC) ou modificada (AM). AM e AC são utilizadas para reduzir a taxa respiratória do fruto, baixar a produção de etileno e controlar insetos e microrganismos. $\mathrm{O}$ armazenamento de mangas a $20^{\circ} \mathrm{C}$ em atmosfera controlada, usando concentrações baixas de $\mathrm{O}_{2}(0,2$ a $0,3 \%)$, pode ser usado para controlar insetos (YAHIA \& HERNANDEZ, 1993). O processo de empacotamento de brócolos, aliado à atmosfera modificada, aumenta a retenção de ácido ascórbico, clorofila e cor sem afetar a atividade da ascorbato oxidase e da peroxidase (BARTH et al., 1993).

Os produtos vegetais podem ser classificados, entre outros critérios, pela intensidade respiratória que vai de menos de $10 \mathrm{mg} \mathrm{CO}_{2} / \mathrm{kg} / \mathrm{h}$ (cebola), considerada muito baixa, a mais de $100 \mathrm{mg}$ $\mathrm{CO}_{2} / \mathrm{kg} / \mathrm{h}$ (brócolos, chicória), tida como extremamente alta (WEICHMANN, 1987). Quando uvas ou outras frutas são colocadas em ambiente fechado, a atmosfera é gradual e naturalmente modificada devido à respiração celular. Sabe-se que gases, como $\mathrm{CO}_{2}$, podem ter efeitos benéficos ou maléficos. Esses efeitos dependem do produto agrícola, da concentração do gás e do período de armazenamento. Enquanto determinadas cultivares de alface não toleram uma atmosfera com teores de $\mathrm{CO}_{2}$ mais elevados que $2 \%$, outras cultivares podem suportar até $15 \%$ (HERNER, 1987).

Algumas empresas que comercializam uvas de mesa têm usado, embora de forma rudimentar, vácuo no início do processo de armazenamento. As bagas, nessas condições, encontram-se em ambiente fechado e, por conseguinte, a composição dos gases nesse ambiente estará em constante modificação. Este trabalho investiga a influência da aplicação do vácuo no início do processo de armazenamento, em temperatura ambiente e sob refrigeração, sobre a formação de metanol, etanol, acetato de etila e etanal nas bagas armazenadas. Avalia também o produto do metabolismo celular mais adequado para ser usado como indicador de deterioração em curso.

\section{MATERIAL E MÉTODOS}

Foram colhidos cachos de uva da cultivar Isabel (Vitis labrusca L.) em um vinhedo do Centro Nacional de Pesquisa de Uva e Vinho da EMBRAPA em Bento Gonçalves/RS. Dois sacos plásticos perfurados, portando três cachos por bolsa, foram transferidos para quatro dessecadores contendo papel de filtro impregnado com $10 \mathrm{~m} \ell$ de uma solução aquosa de $\mathrm{SO}_{2}(36,5 \mathrm{mg} / \ell)$. Cada saco corresponde a uma repetição em cada tratamento. Os tratamentos foram assim distribuídos: (1) dessecador sem vácuo e armazenagem à temperatura ambiente, $25^{\circ} \mathrm{C}$ (TA/S V); (2) dessecador com vácuo inicial, $60 \mathrm{kPa}$ e armazenagem à temperatura ambiente, $25^{\circ} \mathrm{C}$, (TA/CV); (3) dessecador sem vácuo e armazenagem a $4^{\circ} \mathrm{C}\left(4^{\circ} \mathrm{C} / \mathrm{SV}\right)$; e (4) dessecador com vácuo, - $60 \mathrm{kPa}$ e armazenagem a $4^{\circ} \mathrm{C}\left(4^{\circ} \mathrm{C} / \mathrm{CV}\right)$. Nos tratamentos com vácuo, este foi feito uma única vez no início do processo de armazenamento. Os cachos foram mantidos num ambiente de alta umidade relativa (96\%) para reduzir a perda de peso durante o período prolongado de armazenamento. Depois de 30 dias, as bagas de cada cacho foram contadas, examinadas quanto a danos físicos visíveis (rachadura da superfície). Posteriormente, todas as bagas saudáveis e íntegras foram manualmente esmagadas, e o suco resultante foi filtrado em tecido de algodão e submetido imediatamente à análise química. 
O etanol foi determinado por densidade (D) (20/20) e índice de refração (IR), usando densímetro ANTON PAAR e refractômetro Zeiss Jena, respectivamente, cada qual conectado ao banho-maria HAAK-G. A concentração de etanol (G.L.) foi obtida com a expressão seguinte: Etanol = $(2557,19-2585,7 \mathrm{D}+2,6186 \mathrm{IR})$.

As análises de metanol, acetato de etila e etanal foram realizadas em amostras destiladas, contendo 4-metil-propanol-2 como padrão interno. Alíquotas de $3 \mu \ell$ foram injetadas em gás cromatógrafo (CG 3537-D modelo) equipado com detector de ionização de chama e provido de uma coluna aço inoxidável de $2,5 \mathrm{~m}$ (comprimento) $\mathrm{X}$ 4,763mm (diâmetro externo), empacotada com $15 \%$ de polietileno glicol 20M (w/w) em Chromosorb WHP (CG-286-A). O equipamento foi operado isotermicamente. As temperaturas do forno, do injetor $\mathrm{e}$ do detector foram mantidas, respectivamente, a $72^{\circ} \mathrm{C}, 147^{\circ} \mathrm{C}$ e $169^{\circ} \mathrm{C}$. Foi empregado nitrogénio como gás de arraste. Os fluxos de nitrogénio, de oxigénio e de hidrogénio foram de 30, 350 e $30 \mathrm{~m} \ell / \mathrm{min}$, respectivamente. Foram feitas medidas duplicadas para cada amostra.

Foi utilizado o delineamento experimental inteiramente casualizado, com duas repetições. Os resultados foram submetidos à análise de variância e a comparação das médias foi efetuada pelo teste de Tukey $(\mathrm{P}=0,05$ e $\mathrm{P}=0,01)$. Foram efetuadas ainda análises de correlação linear entre as variáveis etanol, metanol, etanal e acetato de etila; e de correlação entre cada um desses componentes formados nas bagas durante o processo de armazenamento e a porcentagem de bagas com danos físicos.

\section{RESULTADOS E DISCUSSÃO}

$\mathrm{O} \mathrm{pH}$ obtido da fruta fresca foi de 3,25. Ao término do experimento, os valores de $\mathrm{pH}$ diminuíram para 3,05 e 3,10 nas bagas mantidas em temperatura ambiente sem e com vácuo, respectivamente. Sob refrigeração, com e sem vácuo, os valores de $\mathrm{pH}$ mudaram, respectivamente, para 3,11 e 3,19.

Os dados apresentados nas figuras $1 \mathrm{a}$ e $\mathrm{lb}$ mostram, respectivamente, os efeitos isolados da temperatura de armazenamento e da aplicação do vácuo, sobre a formação de etanol, metanol, etanal e acetato de etila das uvas. A formação de etanol e metanol nos tratamentos relacionados com vácuo isoladamente não é alterada $(\mathrm{P}>0,05)$, mas é influenciada pela temperatura de armazenamento $(\mathrm{P}<0,01)$. Desses dois componentes, apenas o etanol responde à interação temperatura-vácuo $(\mathrm{P}<0,05)$.
Frutos armazenados continuam respirando e a atividade de respiração depende da atmosfera do recipiente (AGRAVANTE $\boldsymbol{e t} \boldsymbol{a l}$., 1991). A redução de respiração celular não significa necessariamente redução do metabolismo. Os resultados aqui obtidos sugerem ser a atividade das enzimas responsáveis pelo processo de maceração carbónica afetada pela interação temperatura-vácuo.

Resultados referentes ao metanol e etanol produzidos pelas enzimas da baga da uva em cada condição de armazenamento estão apresentados na figura 2A. A concentração mais elevada de metanol, nas bagas submetidas ao armazenamento em temperatura ambiente, e a importante redução desse produto nas uvas mantidas sob refrigeração, mostram o efeito da temperatura sobre a pectinametilesterase. Uma vez que ficou demonstrado que o processo de desesterificação química não ocorre em valores de $\mathrm{pH}$ igual ou maiores que 3,0 (TAILLAN et al., 1992), o processo de desmetilação foi, muito provavelmente, devido à atividade enzimática. Produtos não fermentados podem apresentar concentrações variadas de metanol. No suco de uva fresco da cultivar Isabel, ZANUZ (1991) obteve valores que variaram entre 55 e $69 \mathrm{mg} / \ell$. Analisando 11 sucos de uva, FENOCCHIO \& MENDES (1972) verificaram concentrações de metanol entre 28 e $188 \mathrm{mg} / \ell$. Como a pectinametilesterase e a poligalacturonase agem conjuntamente durante a hidrólise da pectina, a refrigeração pode reduzir problemas de textura de baga durante o armazenamento. Tem sido observado que pectinametilesterase isolada de maçãs altera sua atividade quando armazenada a $8^{\circ} \mathrm{C}$ (KING, 1991).

Os dados apresentados na figura 3 mostram o efeito dos tratamentos sobre a integridade física das bagas. Observou-se que 71,9\% das bagas mostraram-se fisicamente danificadas no tratamento com temperatura ambiente e sem vácuo. Nessa mesma temperatura e com vácuo, a porcentagem de bagas danificadas subiu para $81,8 \%$. A $4^{\circ} \mathrm{C}$, o percentual de bagas danificadas foi de $8,7 \%$ e de $11,9 \%$ nos tratamentos sem e com a aplicação do vácuo, respectivamente. A análise estatística revelou que a refrigeração reduz a quantidade de bagas danificadas $(\mathrm{P}<0,01)$, o vácuo, aplicado no início do processo de armazenamento, atua de modo oposto $(\mathrm{P}<0,05)$ e que a interação temperatura-vácuo não exerce efeito sobre a porcentagem de bagas rachadas $(\mathrm{P}>0,05)$. Os dados indicam que a associação do enfraquecimento da casca da uva, devido à atividade enzimática, com a pressão negativa aplicada no início do processo de armazenamento (-60kPa) faz 


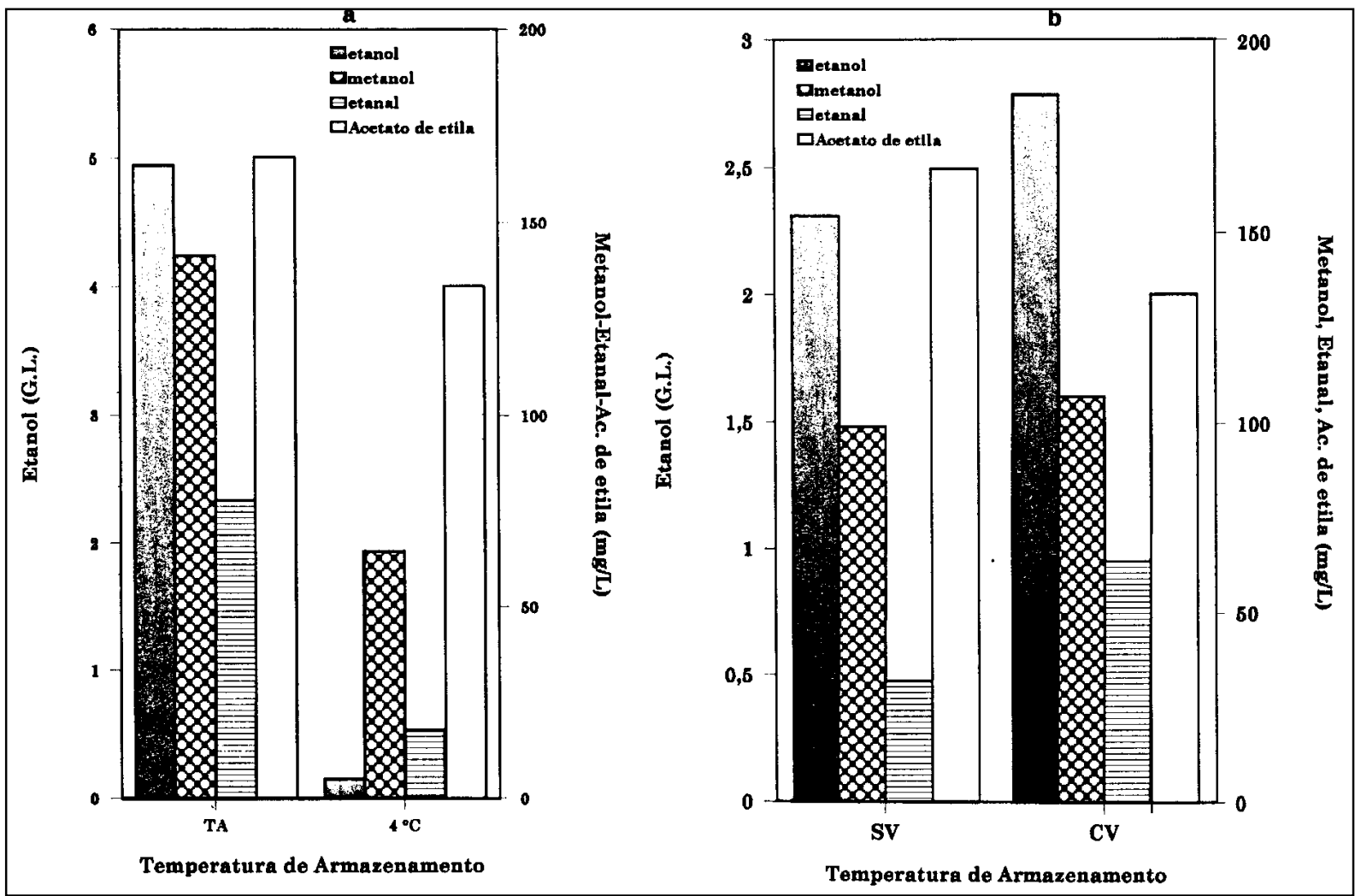

Figura 1 - Teores de etanol, metanol, etanal e acetato de etila em uvas da cultivar Isabel armazenadas em temperatura ambiente (TA) ou a $4{ }^{\circ} \mathrm{C}$ (a) e submetidas ao vácuo no início do armazenamento (b). sem aplicação de vácuo (SV); com aplicação de vácuo (CV).

com que os danos físicos sejam mais pronunciados no tratamento no qual as uvas foram armazenadas em temperatura ambiente e submetidas ao vácuo. $\mathrm{Na}$ prática, a pressão negativa inicial dentro do dessecador vai sendo convertida, gradualmente, em pressão positiva devido à evolução de gás produzido pelo metabolismo das bagas durante o período de armazenamento. Nesse caso, a fragilidade da casca da uva pode estar também relacionada com a composição química da atmosfera circunvizinha.

Sendo a desmetilação um processo enzimático, a desativação das enzimas responsáveis por essa atividade por processos físicos, como o calor, pode reduzir o teor de metanol nas bagas e nos sucos de uva. FENOCCHIO \& MENDES (1972) observaram que os sucos de uva elaborados pelo processo Weich (extração da matéria corante da uva pelo calor) apresentaram, em geral, valores mais baixos de metanol que aqueles elaborados pelo processo Flanzy (extração da matéria corante por maceração sulfurosa à temperatura ambiente). A termoestabilidade da pectinametilesterase tem sido objeto de estudo por diversos autores (RILLO et al., 1992; RIJSSEL et al., 1993) e sua inativação foi obtida a $70^{\circ} \mathrm{C}$ durante 5 min (JAVERI \& WICKER, 1991). Esses fatos tomam o processo de branqueamento da uva para armazenagem impossível, porque a temperatura necessária para inativar a enzima afeta negativamente a cor, sabor e aroma das bagas. Bagas de uvas submetidas à temperatura de $70^{\circ} \mathrm{C}$ apresentaram essas alterações em apenas 15 segundos (dados não apresentados).

As enzimas pectolíticas estão presentes nas uvas em pequena quantidade, mas em concentrações suficientes para causar problemas durante o armazenamento. Tem sido desprendido grande esforço para solucionar problemas de deterioração, impedindo a atividade de enzimas pécticas. TUCKER et al. (1992) consideram a tecnologia RNA anti-senso uma ferramenta capaz de introduzir características comercialmente desejáveis em produtos agrícolas e minimizar os problemas vinculados ao armazenamento e ao transporte. TIEMAN et al. (1992) introduziram gene de pectinametilesterase antisenso em tomates, provocando redução na atividade enzimática sem alterar o processo de maturação. 


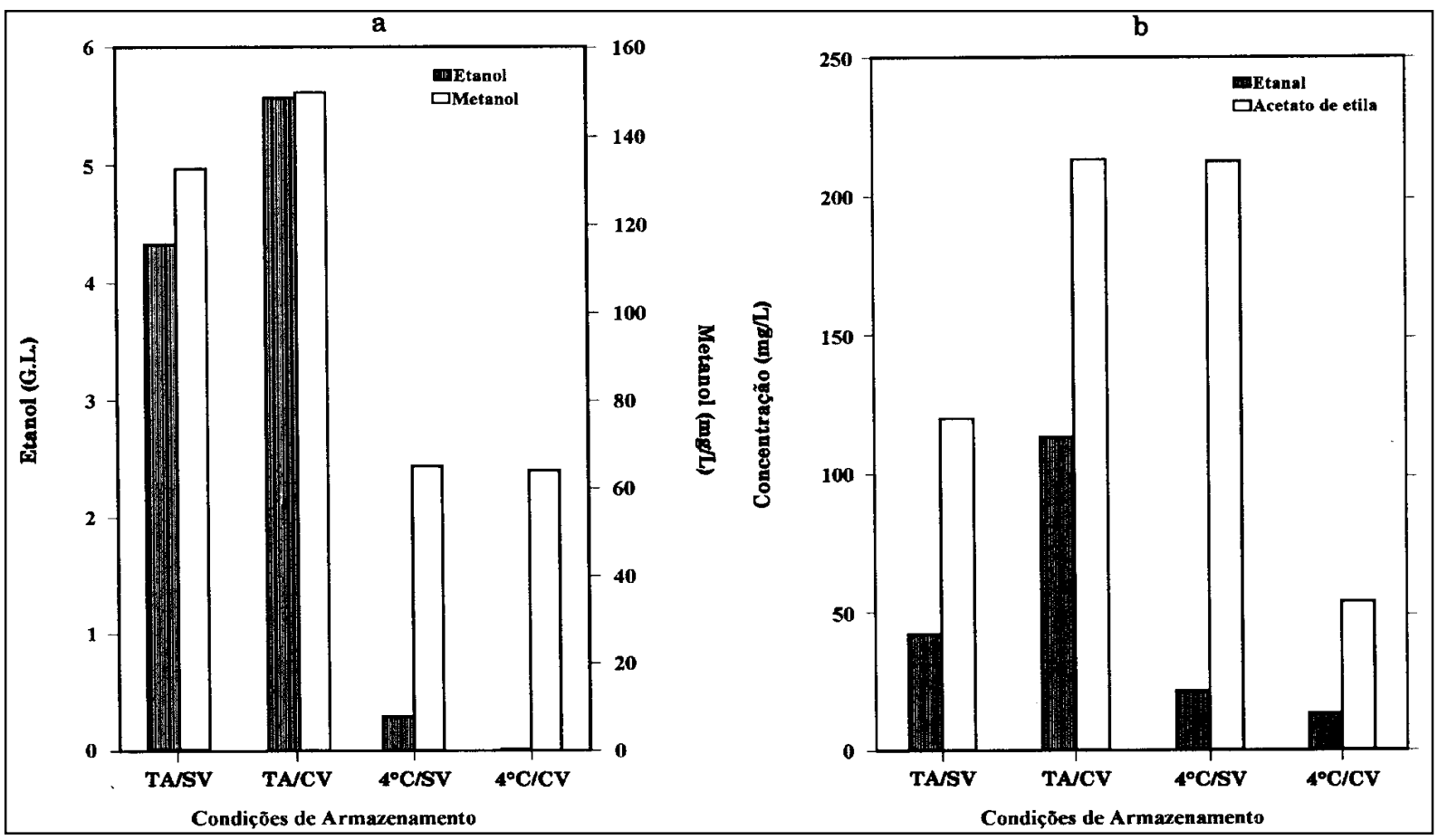

Figura 2 - Concentração de etenol, de metanol (a), etanal e acetato de etila (b) em uvas cv. Isabel mantidas em temperaura ambiente (TA/SV) e com (TA/CV) aplicação de vácuo no início do armazenamento; sob refrigeração sem $\left(4^{\circ} \mathrm{C} / \mathrm{SV}\right)$ e com $\left(4^{\circ} \mathrm{C} / \mathrm{CV}\right)$ vácuo no início do armazenamento.

A produção de etanal se mostrou dependente da temperatura, da aplicação do vácuo e da interação dessas duas condições de armazenamento $(\mathrm{P}<0,01)$. A temperatura e o vácuo, isoladamente, não afetaram a formação de acetato de etila $(\mathrm{P}>0,05)$. Houve alteração na produção deste componente devido à interação desses dois fatores $(\mathrm{P}<0,01)$. $\mathrm{O}$ acúmulo de etanal pode ser estimulado pela presença de $\mathrm{SO}_{2}$. A presença de determinados agentes que se ligam ao grupo aldeído, como $\mathrm{SO}_{2}$, impede que o etanal se comporte como receptor de hidrogénio. Nesse caso, o curso de oxidação do ácido pirúvico é modificado, podendo aumentar não apenas a concentração de etanal, mas também os teores de glicerol e ácido acético. Ácido acético pode reagir com etanol para formar acetato de etila. Os resultados referentes ao etanal e ao acetato de etila formados na baga estão apresentados na figura $2 b$.

Esses metabólitos, com a exceção de metanol, são os mesmos produzidos por leveduras durante o processo de fermentação. Procurou-se determinar a correlação entre os diferentes metabólitos formados e a porcentagem de bagas com rachaduras. Os coeficientes de correlação mostraram que a porcentagem de uvas com rachaduras está positivamente correlacionada apenas com a produção de etanol $(\mathrm{P}<0,01 ; \mathrm{r}=0,990)$, de metanol $(\mathrm{P}<0,01 ; \mathrm{r}=0,996)$ e de etanal $(\mathrm{P}<0,05 ; \mathrm{r}=0,823)$. Os valores mínimos e máximos do etanol foram, respectivamente, 0,01 e 5,57 (G.L.), enquanto que os de metanol foram 64,2 e $149,95 \mathrm{mg} / \ell$. Os valores mínimos e máximos do etanal foram, respectivamente, 13,0 e $117,0 \mathrm{mg} / \ell$. Os resultados sugerem que a evolução de etanol, de metanol e de etanal nas bagas podem servir como sinal importante de alterações químicas e físicas durante o armazenamento. É interessante observar que a formação desses três produtos do metabolismo está também correlacionada entre si $(\mathrm{P}<0,01)$. Os coeficientes de correlação do metanol com etanol e com etanal foram, respectivamente, 0,989 e 0,855, enquanto que o coeficiente de correlação do etanol com etanal foi de 0,861 .

Quanto ao acetato de etila, não se verificou correlação entre a formação deste produto do metabolismo e a porcentagem de bagas com rachadura $(\mathrm{P}>0,05)$ e nem com nenhum outro componente detectado nas bagas da uva $(\mathrm{P}<0,05$; $\mathrm{r}<0,416)$. 


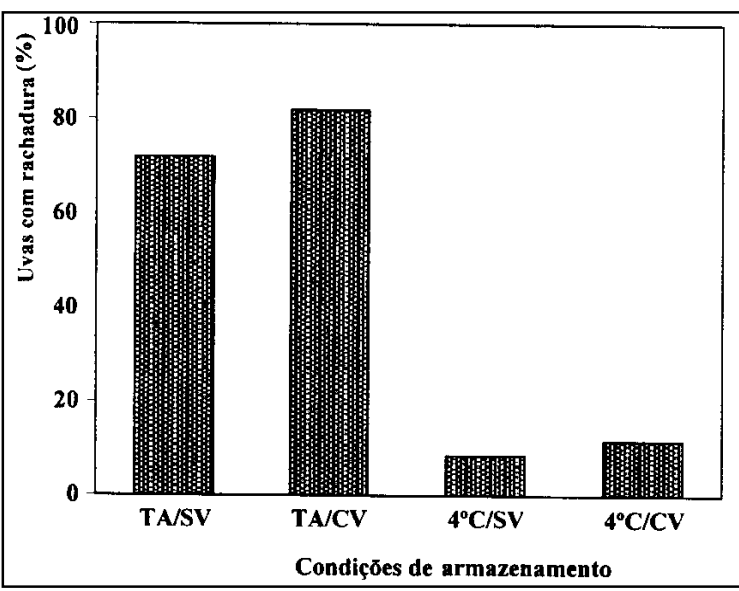

Figura 3 - Porcentagem de bagas de uva cv. Isabel com rachaduras em função da temperatura de armazenamento: (TA/SV) temperatura ambiente sem vácuo; (TA/CV) temperatura ambiente com aplicação de vácuo no início do armazenamento; $\left(4^{\circ} \mathrm{C} / \mathrm{SV}\right)$ refrigeração sem vácuo; $\left(4^{\circ} \mathrm{C} / \mathrm{CV}\right)$ refrigeração com aplicação de vácuo no início do armazenamento.

De um modo geral, foram obtidas, como se esperava, mudanças fisiológicas mais acentuadas nas uvas armazenadas em temperatura ambiente. As análises de etanol, etanal e, especialmente, de metanol em uvas mantidas em temperatura ambiente com ou sem vácuo podem representar uma forma prática de medir ganhos de qualidade de uma determinada cultivar em programas genéticos destinados à obtenção de uvas de mesa menos sensíveis ao processo de deterioração.

\section{AGRADECIMENTOS}

O autor agradece à Doutora Loiva M. R. de Mello pela leitura crítica deste manuscrito e às técnicas de laboratório, Maria A. L. Morini, pela valiosa ajuda na execução deste trabalho, Vânia M. A. Sganzerla e Nilda. M. G. Zucco pelas análises químicas efetuadas.

\section{REFERÊNCIAS BILBIOGRÁFICAS}

AGRAVANTE, J.U., MATSUI, T., KITAGAWA, H. Changes in pectinmethylesterase, polygalacturonase and pectic substances of ethanol-and ethylene-treated bananas during ripening. Nippon Shokuhin Kogyo Gakkaishi, v.38, p.527$532,1991$.

BARTH, M.M, KERBEL, E.L., PERRY, A.K, et al Modified atmosphere packaging affects ascorbic acid, enzyme activity and market quality of broccoli. Journal of Food Science, v.58, p.140-143 1993.

FENOCCHIO, P., MENDES, M. Teores de metanol nos sucos de uva brasileiros. Pelotas: Ministério da Agricultura, Departamento Nacional de Pesquisa Agropecuária, Instituto de Pesquisas Agropecuárias do Sul, 1972. 8p. (Boletim Técnico, 82).
FOGARTY, W.M., WARD, O.P. Pectic substances and pectinolytic enzymes. Process Biochemistry, v.7, p.13-17, 1972.

HERNER, R.C. High $\mathrm{CO}_{2}$ effects on plant organs. In WEICHMANN, J. Postharvest of physiology of vegetables. 10 ed. New York : Mercel Dekker, 1987. cap.ll. p.239-253.

JACKMAN, R.L., GIBSON, H.J., STANLEY, D.W. Effects of chilling on tomato fruit texture. Physiologia Plantarum, v.86, p.600-608,1992.

JAVERI, H., WICKER, L. Partial purificadon and characterization of peach pectinesterase. Journal of Food Biochemistry,v.15,p.241-252, 1991.

KING, K. Characteristics of pectinesterase isolated from Bramiey apple waste. Journal of the Science of Food and Agriculture, v.57, p.43-48, 1991.

LIU, K., PHILLIPS, R.D., HUNG, Y-C. Development of hard tocook defect in cowpeas: role of pectin methylesterase. Journal of Agricultural and Food Chemistry, v.40, p.949952,1992

MANJÓN, A., BORRA, J.L., ROMERO, C. et al Properties of pectinesterase and endo-D-polygalacturonase coimmobilized in a porous glass support. Applied Biochemistry and Biotechnology, v. 37, p. 19-31,1992.

PRESSEY, R., WOODS, F.M. Purification and properties of two pectinesterases from tomatoes. Phytochemistry, v.31, p.11391142,1992 .

RIBÉREAU-GAYON, J., PEYNAUD, E., RIBÉREAU-GAYON, P., et al. Traité d'0enologie Sciences et Techniques du Vin. Bordas, Paris : Dunod, 1976. cap.6: Vinification avec macération carbonique: p.289-314.

RICHARDSON, T., HYSLOP, D.B. Enzymes. m: FENNEMA, O.R. Food chemistry. 10 ed. New York: Mareei Dekker, 1985. cap.6. p.371-476.

RIJSSEL, M. VAN, GERWIG, G.J., HANSEN, T.A. Isolation and characterization of an extracellular glycosylated protein complex from Clostridium thermosaccharolyticwm with pectin methylesterase and polygalacturonate hydrolase activity. Applied and Enviromnental Microbiology, v.59, p.828-836,1993.

RILlO, L., CASTALDO, D., GIOVANE, A., et $\boldsymbol{a}$. Purification and properties of pectin methylesterase from mandarin orange fruit. Journal of Agricultural and Food Chemistry, v.40, p.591-593,1992.

TAILLAN, E., AMBID, C., PECH, J.C., et al. Demethylation of pectic substances: relationship to methylesterase activity during brine storage of cherries. Journal of Food Science, v.57, p.682-685,1992.

TIEMAN, D.M., HARRIMAN, R.W., RAMAMOHAN, G., $\boldsymbol{e}$ t al . An antisense pectin methylesterase gene alters pectin chemistry and soluble solids in tomato fruit. Plant Cell, v.4, p.667-679, 1992.

TUCKER, G.A., SEYMOUR, G.B., BUNDICK, Y., et al. Use of antisense RNA technology to study pectin degradation in tomato fruit. New Zealand of Crop and Hortículture Science, v.20, p.1 19-124, 1992. 
WEICHMANN, J. Vegetables: Classification and definition of In: WEICHMANN, J.. Postharvest of physiology of vegetables. 10 ed. New York : HortScience, v.28,p.1031, 1993.

WHISTLER, R.L., DANIEL, J.R. Carbohydrates. In FENNEMA, O.R. Food Chemistry. 10 ed. New York: Mareei Dekker, 1985. cap.3. p.69-137.
YAHIA, E.M., HERNANDEZ. M.T. Tolerance and responses of harvested mango to insecticidal low-oxygen atmospheres. HortScience, v.28, p.1031, 1993

ZANUZ, M.C Efeito da maturação sobre a composição do mosto e qualidade do suco de uva. $177 \mathrm{p}$. Dissertação (Mestrado em Fitotecnia) - Curso de Pós-graduação em Agronomia, Universidade Federal do Rio do Sul, 1991.

Ciência Rural, v. 30, n. 4, 2000. 